\section{Entre o Riso e o Trágico: Perspectivas sobre Modos de Vida no Brasil Entrevista com Donna M. Goldstein}

Dol

http://dx.doi.org/10.11606/ 2179-0892.ra.2019.165237

Por

Arielle Milkman University of Colorado Boulder, Anthropology, College of Arts and Sciences | Colorado, United States Arielle.Milkman@ colorado.edu

\section{Susana Durão} Universidade Estadual de Campinas, Instituto de Filosofia e Ciências Humanas, Departamento de Antropologia | Campinas, SP, Brasil ssbdurao@gmail.com

Donna M. Goldstein é uma antropóloga médica e cultural de renome internacional que trabalhou no Brasil por cerca de trinta anos. Ao longo de sua trajetória, apresentou importantes contribuições para os estudos acadêmicos sobre o ativismo HIV/aids, a política farmacêutica no México e na Argentina, o nacionalismo e o antissemitismo na Hungria, sobre o humor no contexto de políticas raciais, de classe e de gênero, e sobre violência cotidiana. Seus estudos mais recentes concentram-se em investigações acerca de ciência, medicina e meio ambiente no contexto de toxicidade e incerteza observado nos Estados Unidos e no Brasil. Coldstein é professora de antropologia na Universidade do Colorado, onde atua desde 1994. É cofundadora do Latin American Studies Center (LASC) [Centro de Estudos Latino-Americanos] na Universidade do Colorado, do qual foi diretora de 2014 a 2017.

Quatorze anos após a publicação original de Laughter Out of Place: Race, Class, Violence, and Sexuality in a Brazilian Shantytown [O riso fora do lugar: raça, classe, violência e sexualidade em uma favela brasileira], o livro continua a repercutir entre leitores de obras de antropologia, tanto nos EUA como no Brasil. Laughter ganhou o prêmio Margaret Mead em 2004 por suas corajosas reflexões sobre violência cotidiana, gênero, raça, classe e humor negro nas favelas do Rio de Janeiro. O enfoque da etnografia de Coldstein na moradora Clória e sua família vai na contramão das teorias da "cultura da pobreza" e lança questionamentos acerca dos efeitos do "milagre" econômico do Brasil, bem como põe em questão o significado da democracia racial brasileira na vida de mulheres que vivem na margem da capital carioca. $\mathrm{O}$ atual projeto de pesquisa de Coldstein trata da história da ciência na Guerra Fria e foca a produção de energia nuclear no município brasileiro de Angra dos Reis (RJ).
ORCID

https://orcid.org/ 0000-0002-6928-2697

https://orcid.org/ 0000-0001-8096-6806 
Donna Goldstein é natural de Nova York. Graduou-se em sociologia rural na Universidade Cornell e fez mestrado em psicologia educacional na Universidade de Harvard. Goldstein viajou por toda a América Latina, integrando equipes de pesquisa que investigavam economias camponesas e reforma agrária; viveu no Equador por dois anos e meio e, no México, por quase um ano antes de retornar aos EUA e se matricular na Universidade da Califórnia, em Berkeley para realizar seu doutorado. Depois de passar um ano no departamento de psicologia da universidade, Coldstein ingressou no programa de antropologia em 1989, sob a orientação da antropóloga brasilianista Nancy Scheper-Hughes. Na pesquisa de campo que realizou no Rio de Janeiro, para sua tese de doutorado, Goldstein investigou o ativismo HIV/aids e o engajamento das mulheres nessa militância. Foi nesse contexto que ela conheceu Clória, pseudônimo de sua principal interlocutora em Laughter out of Place.

No prefácio à segunda edição (2013) do livro, Goldstein reflete sobre as mudanças (já bastante conhecidas) nas condições das favelas do Rio em que ela trabalhou. Ela descreve que naquele momento, no Brasil, os políticos exibiam estatísticas internacionais de desenvolvimento para elogiarem o crescimento do PIB nacional e a redução da desigualdade de renda, enquanto que trabalhadoras domésticas, a exemplo de Glória, nos fazem pensar sobre quem estaria usufruindo das benesses do crescimento da posição do Brasil no cenário global de então. Em seguida, Goldstein descreve a implementação do programa de pacificação em algumas das mais notórias favelas do Rio, em preparação para a Copa do Mundo de Futebol da FIFA de 2014. Ao mesmo tempo, na perspicaz análise que Coldstein apresenta sobre o Rio em mutação, as intersecções entre violência e humor estão sempre presentes, especialmente quando ela relata um episódio em que passageiros de um ônibus descrevem uma angustiante narrativa de sequestro em São Paulo - para o deleite e gargalhadas de outros passageiros.

Se o trabalho etnográfico de Goldstein na década de 1990 expõe "algo trágico e de humor sombrio sobre as condições das pessoas - principalmente mulheres de pele escura - vivendo em comunidades marginalizadas" (Goldstein, 2013), sua obra mais recente mantém o compromisso de examinar cuidadosamente "formas silenciosas de violência" e marginalidade. Em seu trabalho de pesquisa atual, a autora busca enquadrar os efeitos dos perigos e danos invisíveis como toxicidades ambientais (Goldstein, 2017a) e entender os efeitos de discursos produzidos por meio da elaboração do conhecimento científico sobre populações pobres que vivem nas periferias urbanas.

Coldstein nos leva a Angra dos Reis, lugar fundamental para a biodiversidade e para o ecoturismo na parte sul do estado do Rio de Janeiro, e cidade sede da única usina nuclear do Brasil. Em Angra, ela realizou entrevistas, entre 2012 e 2015, com engenheiros, assistentes sociais, ativistas e profissionais de 
saúde pública que dialogavam com a Central Nuclear Almirante Álvaro Alberto (CNAAA). No momento, Goldstein está escrevendo um livro baseado nessa pesquisa, intitulado Brazil's Nuclear Ambitions: From Cold War Science to Contemporary Populations at Risk [Ambições nucleares do Brasil: da ciência da Guerra Fria às populações contemporâneas em risco], no qual rastreia as conexões entre o sigilo da Guerra Fria e regimes científicos contemporâneos, bem como as questões que a ciência deixa "inacabadas" ou "inquestionadas". Enquanto isso, ela demonstra como as populações próximas a Angra dos Reis são atingidas pela desigualdade econômica, pela infraestrutura desequilibrada e pela "formação de camadas tóxicas" (Hall, Coldstein \& Ingram, 2016) ou de diferentes toxicidades, que, em conjunto, reforçam potencialmente a precariedade e tornam impossível para os cientistas diagnosticar uma fonte única de risco ou um problema de saúde pública exclusivo (Goldstein, 2017a, 2017b). Para complicar ainda mais as coisas, a usina de Angra dos Reis está atualmente envolvida em um escândalo nacional de corrupção de proporções épicas. Esta é, de fato, uma conhecida "violência lenta" (Nixon, 2011), tal como já era aquela que se encontrava presente em Laughter Out of Place. No entanto, o trabalho atual de Coldstein também está fortemente preocupado com a produção de narrativas de risco global e local (Beck 2006, 2007; Coldstein 2017d) e com as subjetividades particulares (Goldstein 2017a) que vêm à tona em situações de degradação e contaminação ambiental. De fato, no número especial do volume Culture, Theory and Critique, editado por Coldstein (2017a) e intitulado Invisible Harms: Science, Subjectivity, and the Things We Cannot See [Danos invisíveis: ciência, subjetividade e as coisas que não podemos ver], a autora se debruça sobre a incerteza, a ambivalência e sobre as "trevas epistêmicas" que emergem entre a (des)informação adjacente a encontros tóxicos. Ao longo desse volume, Goldstein (2017a) baseia sua análise em dados etnográficos meticulosos e minuciosos, sugerindo que podemos tratar a produção de energia nuclear, por exemplo, como uma montagem sócio-material, rica em termos descritivos e profundamente significativa, tanto para humanos como para não humanos.

Em outros textos, Goldstein refletiu sobre o papel da etnografia contemporânea. ${ }^{1}$ Nesses escritos, ela expressou uma preocupação acerca da melhor maneira de escrever sobre a vida dos outros, no sentido de evitar reduzir a riqueza da experiência humana. Os etnógrafos - especialmente estudantes e acadêmicos de campos interdisciplinares, como os Estudos Sociais da Ciência e da Tecnologia, também denominados Estudos sobre Ciência, Tecnologia e Sociedade, Estudos de Ciência, Tecnologia e Sociedade ou Estudos de Ciências-Tecnologias-Sociedades (CTS) -, talvez julguem que falta aos antropólogos as habilidades técnicas e afetivas para cativar adequadamente nossos interlocutores, tornando difícil, senão impossível, retratar sua vida, preocupações e inter-
1 Ver Coldstein (2018), "Beyond Thin Description: Biography, Theory, Writing" [Além da descrição rarefeita: biografia, teoria, escrita] e Coldstein (2017e), "Fieldnote as Political Weapon: James Comey's Ethnographic Turn?" [A anotação de campo como arma política: a guinada etnográfica de James Comey?]. 
esses de maneira precisa. Mas Coldstein supera essa dificuldade, amalgamando teoria, descrição etnográfica densa e cultura pública, sem minimizar suas complexidades e contradições. Neste momento histórico em que antropólogos culturais estão pensando profundamente sobre o papel da escrita etnográfica, e por vezes questionando esse papel (Peirano, 1995; Ingold, 2014; Jackson Jr, 2012; McGranahan, 2015), Goldstein reafirma o valor da densidade etnográfica, combinando biografia, economia política e teoria crítica. Essa atenção a uma antropologia mais ampla (Ortner, 1984) também é evidente na análise que Hall, Goldstein e Ingram (2016) apresentam sobre o uso que Donald Trump faz do humor e do gesto, simulando armas; e também do uso que faz da nostalgia racista politizada e da política do "apito de cachorro"2 para falar com partidários nacionalistas brancos durante as eleições presidenciais norte-americanas de 2016 (Goldstein e Hall, 2017).

Tivemos a oportunidade de nos reunir com a professora Coldstein em maio de 2017. Falamos do processo e da política de escrita de Laughter Out of Place, bem como da circulação e da recepção do livro no decorrer dos últimos quatorze anos. Nessa conversa vieram à baila temas como o significado do humor, 0 capitalismo tardio e o neoliberalismo e o avanço dos conservadores nos Estados Unidos e no Brasil. Discutimos também a participação do Brasil nas corridas nucleares globais durante a Guerra Fria, o desenvolvimento de um programa brasileiro de energia nuclear e as questões que animam a política contemporânea com relação à corrupção e à modernidade no Brasil. Por fim, encerramos a conversa com questões sobre o papel da antropologia e da etnografia na contemporaneidade. Sentimo-nos afortunadas por ter iniciado esta colaboração e pretendemos manter um diálogo produtivo entre as comunidades acadêmicas no Brasil e dos EUA.

\section{Em 2003, seu livro Laughter Out of Place foi recebido com controvérsia, tal como} Nancy Scheper-Hughes e Philippe Bourgois previam no prefácio que escreveram?

DG-Meu maior medo com Laughter, em 2003, era que meus amigos brasileiros mais próximos, que eram das classes médias, ficassem zangados comigo - por possivelmente acharem que havia sido muito crítica com relação às questões de raça e de classe no Brasil. Naquele momento não havia consenso entre acadêmicos das humanidades. Havia também algumas questões relacionadas a disputas acadêmicas, problemas que podem ocorrer quando antropólogos não nativos realizam trabalho de campo, e eu estava ciente de tudo isso porque havia sido orientada por Nancy Scheper-Hughes. Uma coisa óbvia para qualquer antropólogo trabalhando no Brasil é o dever de familiarizar-se com os trabalhos brasileiros sobre o Brasil e citar os autores apropriadamente, dando-Ihes o merecido respeito em seus textos. Nesse
2 Referência a "dog-whistling", o som de apito que apenas os cães conseguem ouvir; no jargão da política norte-americana, o termo alude ao som que só um determinado grupo militante é capaz de ouvir. Assim, a "política do apito do cachorro" é baseada em um código partilhado por grupos específicos; trata-se de uma mensagem política dirigida a um grupo que domina o código e é capaz de entender seus significados, um tipo de discurso que parece significar uma coisa para a população em geral, mas que tem um significado diferente para uma parte específica do público. (n. t.) 
sentido, sinto que meu livro não foi controverso, uma vez que segui esse princípio e fui muito cuidadosa nas leituras que fiz dos autores brasileiros.

Acho que, muitas vezes, o que uma boa etnografia faz é, infelizmente, capturar algo que todos já conhecemos. Em 2003, todos sabíamos que não havia mais como ignorar a política racial no Brasil. Este tema havia causado controvérsia nos trinta anos anteriores; por exemplo, com questões em relação a como o Brasil deveria a poiar seu movimento afro-brasileiro, a como deveria buscar novas formas de inserção na sociedade civil e em relação ao debate sobre por que meios o país poderia se tornar mais democrático e igualitário. As discussões sobre raça poderiam ser utilizadas como base para isso. Essas controvérsias realmente antecederam e penetraram a minha pesquisa ao longo dos anos de 1990. Nos anos 2000 elas floresceram. Mas acho que em 2003, a maior parte dos intelectuais já estava convencida de que o Brasil realmente precisava pensar nisso. Meu livro foi lançado nessa época, e embora não fizesse grandes sugestões políticas, ele produziu uma imagem de um lugar que precisava ser pensado a partir desse problema da raça. Nesse sentido, não acho que o livro foi recebido com controvérsia. Costo de pensar que Laughter Out of Place foi lido no Brasil. Ele ganhou o Prêmio Margaret Mead de antropologia, em 2004, e por isso obteve alguma atenção nos Estados Unidos. Mas talvez o livro não tenha ocupado um lugar de destaque nos meios acadêmicos brasileiros: o que uma antropóloga norte-americana pode dizer a um brasileiro a respeito do dia a dia no Brasil?

\section{Você recebeu comentários dos seus amigos brasileiros a respeito do livro?}

DG-Eles foram muito gentis e encorajadores. Muitos deles eram acadêmicos mais velhos, que realmente não tinham problemas de ego, e que são pessoas incrivelmente generosas e simpáticas. Talvez pensassem que eu tivesse sido um pouco dura demais em algumas partes do livro, mas, por outro lado, não havia nada com que não concordassem. E foram generosos, pois estavam mais avançados do que eu em suas carreiras. Acho que esse livro estava falando com a geração mais jovem de acadêmicos, que estava chegando. Mais tarde, tive a oportunidade de ser supervisora de pós-doutorado de um antropólogo brasileiro que esteve aqui na Universidade de Boulder e de dois outros pós-doutorandos. Espero que seja essa a atitude correta: ser generoso com os novos pesquisadores, com os novos trabalhos e com a tomada de novos rumos. Evidentemente, as pessoas ofereceram críticas ao livro, mas não foram críticas devastadoras. Acho que o livro foi resenhado mais de trinta vezes, por isso houve uma série de comentários registrados nele. Ele foi resenhado em francês, em espanhol e em português, mas a maior parte das resenhas foi em inglês. Ele também ganhou uma página inteira 
no Jornal do Brasil e uma página inteira na Folha de São Paulo. Nessa época, final da década de 1990, ter ficado tanto tempo nas favelas do Rio parecia, para os próprios acadêmicos brasileiros, muito corajoso. Receber elogios por fazer o que todos fazem, vivendo lá, é algo tolo, mas foi isso que os jornais assumiram e escreveram sobre o meu trabalho de campo nas favelas. Posso ter recebido críticas, mas fui poupada a questionamentos como: "o que você está fazendo aqui?", "qual papel você desempenha?", "por que você está aqui?". Fui poupada disso.

A região em que você trabalhou mudou muito desde que você escreveu o livro?

DG - Entre 2003 e 2017, muitos desses bairros no Rio foram, aos poucos, gentrificados por jovens hipsters e artistas, de maneira semelhante ao que ocorreu em Nova York, Roma e São Francisco. Tenho um aluno, Jason Scott, que esteve mais recentemente no Brasil e morou em alguns bairros que foram gentrificados no Rio e que passaram por um processo semelhante ao que aconteceu nos EUA. Sua pesquisa é sobre as interações entre os moradores locais, comunidades hipsters e as pessoas que competem pelo setor imobiliário. Ao mesmo tempo, esses lugares convivem com a violência policial e ali perdura a incerteza cotidiana que eu e outros descrevemos para outros lugares da cidade. Se pensarmos nos bairros em torno da Universidade de Columbia, em Nova York, nos últimos vinte anos. Não são fenômenos diferentes. Voltei suficientes vezes ao Rio para saber que as coisas mudaram. Todos estavam preocupados e isso era difícil porque, como agora sabemos, havia todo um nível de violência cotidiana e de fações que estavam fora do controle. Você pode chamar de um Estado paralelo, ou de um Estado falido, ou apenas de crianças de 12 anos armadas. Mas a verdade é que era realmente desconcertante.

O livro fala de como o humor, a ironia e todos os meios ambivalentes de se comunicar e sentir se entrelaçam com o sofrimento cotidiano nas relações sociais, tanto na família quanto nos locais de trabalho. Você tece de forma convincente esses modos afetivos de ser, relatando diversas formas históricas e situacionais de desigualdade, precariedade, violência e sexualização da negritude no Brasil, particularmente nessa favela situada na zona oeste do Rio de Janeiro. Você considera que o seu livro faz parte da virada afetiva [affective turn], tão prevalente na antropologia atual? DG-Sou um pouco anterior à teoria do afeto [affect theory], mas acho que o que eu estava tentando fazer naquele momento é muito similar ao que boa parte dos pesquisadores que se identificam com dessa teoria está tentando fazer agora. É também o tipo de coisa que você encontra no bom jornalismo - como The New Yorker, por exemplo-, que chamam a esse tempo a "dé- 
cada cínica" ou "década irônica", e que agora chamam a atual de "década da mentira". Eu realmente precisava entender os afetos em jogo para escrever sobre o que observava. O melhor meio para eu alcançar isso foi através das brechas do humor, mas que no início não eram inteiramente claras. Resisti ao meu próprio projeto por muito tempo. Eu pensava em contar às pessoas o que realmente estava acontecendo em relaçao à aids. Meu interesse primeiro era pesquisar e escrever sobre HIV e aids e todas as coisas relacionadas isso. Mas o que eu realmente sentia era que o humor e o afeto estavam por trás de tudo: do modo de funcionamento das coisas, do fracasso das coisas e de como as pessoas lidavam com isso no dia a dia. Finalmente, eu rejeitei todas as outras versões do meu projeto e quando comecei a redigir Laughter Out of Place comecei a falar muito mais da minha experiência de campo e do que meu coração me indicava do que de todas as outras aferições que eu havia feito antes.

\section{Do seu ponto de vista, qualé a maior contribuição do livro?}

DG - Espero que este represente um retrato do Rio na segunda metade da década de 1990. De certa forma, Laughter dá um passo adiante nos interesses narrativos da antropologia. Mas o livro é, concretamente, uma tentativa de realizar um trabalho sobre afeto, economia política e violência urbana. Revela as complicações de uma família extensa e analisa questões raciais, de classe e de intersecção que estavam visíveis no final da década de 1990. Eu própria conversei com amigos e outros colegas que têm utilizado o livro nos seus programas de ensino. Por isso creio que o trabalho pode oferecer a futuros brasilianistas um meio de compreender formas de desigualdade que em vez de desaparecer estão de novo se agudizando. Como sabemos, houve um grande otimismo durante a era Lula: grandes programas de governo. Mas injustiça e pobreza enraizadas não mudam de um dia para o outro. Espero ter fornecido uma base histórica para que os iniciantes nos estudos brasileiros possam perceber as dificuldades destes temas.

Laughter Out of Place é uma obra que teve sua própria vida e que me permitiu ver novos horizontes. Levou 14 anos para ser realizada. Mas os temas do humor, riso e seus entendimentos me levaram mais longe. Recentemente, fui coautora de dois artigos sobre Donald Trump (Hall, Goldstein e, and Ingram, 2016; Goldstein eand Hall, 2017), com uma proposta de análise de suas rotinas cômicas e dos efeitos que essas rotinas produziram na campanha presidencial. Não critico a literatura sobre humor, mas sempre me pareceu que esta frequentemente existia num vácuo algo folclórico. E eu realmente queria trazer uma dimensão crítica à tona. Era preciso mostrar que tipos de conhecimento as comunicações humorísticas produzem e provar 
que têm a sua própria força retórica e semântica.

Eu também considero oportunos os artigos sobre o Trump porque acho que a maioria de nós não estava ciente do que naquele momento estava acontecendo, como no Brasil de certo modo aconteceu com Bolsonaro. Algo aparentemente tão banal como o humor, a rotina cômica ou a imitação, passaram para a ribalta, de um modo que a esquerda liberal realmente não podia prever. Uma das coisas que o humor fez no Brasil, e faz nos Estados Unidos, tem a ver com a forma como mascara a comunicação, permitindo dizer coisas diferentes a pessoas diferentes. É muito fácil criar mal-entendidos. Resisti ao humor como um tema organizador do social por bastante tempo. Eu dizia a mim mesma: "Não sei se quero organizar algo em torno disso; parece pouco robusto". Mas na verdade, o humor realmente não é pouco, e de fato me ajudou a ver os dados de modo diferente.

\section{Conhecendo você pessoalmente, posso dizer que o tema do humor se encaixa na} autora [risos].

DG - Definitivamente [risos]. O modo de se comunicar no Brasil se tornou, para mim, uma maneira de conhecer realmente as pessoas em um nível diferente de intimidade. Eu era a pessoa mais branca naquela favela e, com certeza, eu tive de esconder coisas da minha própria vida naquela época. Mas, de fato, senti que entendendo o humor atingia um outro patamar de comunicação com as pessoas.

\section{Você mantém contato com seus amigos e informantes de Laughter Out of Place?}

DG - Eu tentei, mas a última viagem (em 2015) foi meio problemática. Liguei para as pessoas para quem trabalhava a minha informante principal, Clória. Eu já havia falado por Skype com seus patrões que moravam em Copacabana anos antes. Soube que Clória se aposentara. Na última conversa, percebi que eles não estavam mais morando no mesmo apartamento onde ela havia trabalhado diariamente durante anos. De modo que perdi o rastro de todo o mundo. Eu não tinha mais o seu número de celular. Então, nessa última viagem, em 2015, eu não a revi. Percebi também que os pontos de referência na estrada, que indicam a saída do Rio, não estavam lá mais. Como chegar onde ela vivia? Em vez dos pontos que conheci havia agora passarelas, justamente onde antes estava essa pequena favela empoeirada onde residia Clória. Passei pelo lugar mas não cheguei a me aventurar a entrar à procura de Clória e de sua família.

Agora eu não tenho como entrar em contato com a Clória. Estou triste por isso, e também porque gostaria de reencontrar essas antigas crianças com quem convivi, mais de 16. Há muitas pessoas que gostaria de encontrar que 
agora estão adultas e com seus próprios filhos; talvez alguns dos mais velhos já tenham até netos. Mantive contato regular com eles até 2008 , mas a partir de então eles começaram a se mudar, ir embora para diferentes lugares. $\mathrm{E}$ isso tem a ver com as flutuações da violência em diferentes comunidades. No início, eu telefonava para o orelhão e eles subiam para chamar alguém e diziam: "Ei, a gringa “'Danni" (como me chamavam) dos EUA está ligando", e subiam para achar alguém. Mas os orelhões foram desativados, por volta de 2008, quando todos passaram a usar telefones celulares. Eu nunca tive o número do celular da família da Glória. Uma vez liguei para o orelhão e ouvi outros vizinhos que eu desconhecia falarem: "Eles foram embora, se mudaram pra longe". Se eu voltasse este ano e fosse exatamente ao lugar onde morou Clória talvez eu conseguisse alguém que me desse um endereço. Embora não esteja muito otimista a respeito, acho que seria bom arriscar.

\section{Na introdução da edição de 2013, você fala de uma viagem de volta ao Rio e de certa violência, dizendo: "Ei, talvez isso não seja o que eu quero fazer agora". Pode comen- tarisso?}

DG - Nas últimas semanas da pesquisa de campo para a minha tese eu já estava no Brasil há quase três anos. Eu havia prolongado a minha pesquisa de campo, porque eu realmente gosto muito de fazer trabalho de campo. Eu acabei ficando mais tempo do que o previsto. Talvez seja por isso que é difícil para mim voltar aos mesmos lugares anos mais tarde. Eu realmente prolongo muito a estadia, tão longa quanto minha alma possa permitir, de modo que voltar é muito difícil. Eu fui estudante na Universidade de Berkeley e tenho dificuldade em visitar o campus com frequência. Estive em São Francisco para visitar amigos, mas a Berkeley, ao meu café da esquina, ao lugar onde escrevi minha tese, ao departamento de antropologia, tenho dificuldade em voltar. Há uma espécie de nostalgia etnográfica.

Na semana em que estava prestes a deixar o Brasil, em 1993, tive uma série de problemas. Ao longo de dez horas, roubaram o apartamento de uma grande amiga, eu fui roubada e várias outras coisas deram errado. Interpretei isso como: "Ok, o meu anjo da guarda está em greve; preciso ir embora agora". Eu meio que tomei isso como um sinal de que eu deveria partir. Mas me senti ambivalente e insegura, como a maioria das pessoas quando deixa o seu campo de trabalho após muito tempo de imersão. "Terei o suficiente? Compreendo tudo? Estou realmente indo para casa para escrever?”. Eu estava triste por deixar para trás tantas pessoas. Não sabia quando voltaria. Sabia que a comunicação também seria um pouco difícil. Em 1993, a comunicação pela internet estava apenas começando. Quem a utilizava o fazia por empréstimo. Eu acompanhava meus amigos e informantes através de suas 
patroas. Além do mais, ninguém escrevia cartas. Eu sabia que era hora de ir, mas era triste ter de ir embora. Muita coisa estava acontecendo...

$\mathrm{Na}$ última vez em que eu estive no bairro que eu chamo de Felicidade Eterna, todos tivemos que fugir da favela porque estava havendo uma pequena guerra de fações e as pessoas estavam sendo tomadas como parte de cada lado. Estávamos todos sendo usados como reféns. Então partimos e foi uma situação muito desagradável. Isto para não mencionar os assaltos estúpidos que aconteceram. Não gosto muito de falar disso, porque obviamente no Brasil - Rio e São Paulo - há severas repressões à violência urbana e a violência institucional é absurda.

\section{Entretanto, seus interesses de pesquisa evoluíram e mudaram drasticamente, mas} alguns temas permaneceram. Você poderia contar como chegou ao seu novo projeto sobre energia nuclear no Brasil?

DG - Eu gosto de estar sempre numa curva íngreme de aprendizado, e gosto de ler novos materiais. Estou muito fascinada com coisas que vão além da etnografia detalhada. Nos anos 1990, sentíamos que a etnografia dava voz a pessoas que não podiam se organizar. Podia ser ingênuo e tolo, mas sentíamos assim. Não havia sindicatos de trabalhadores domésticos naquela época, nem regras para atribuição de salários. No final da década de 80 e na década de 90, se falava no salário mínimo, que era lamentável no Brasil. E eu realmente queria mergulhar naquela desigualdade e tentar dizer algo novo a esse respeito. Mas, por outro lado, também saí da graduação com muitas horas de aulas de ciência, muito interesse em tecnologia e naquilo que podemos chamar de capitalismo tardio e modernidade. E então, como amadureci, e como a antropologia começou a fazer novas perguntas, os meus interesses começaram a mudar. Nesse contexto, o meu interesse na pandemia de HIV/aids, nos anos 1980 e 1990, foi transformado. Em minha pesquisa de campo no Brasil, também estudei o ativismo em relação ao HIV/ aids. Na verdade, minha tese é também sobre HIV/aids no Brasil, sobre esses projetos que foram criados para proteger as mulheres num meio em que a sexualidade era celebrada. Era uma época interessante para realizar essa investigação. Mas o tema do HIV/aids mudou muito rápido e as coisas se transformaram subitamente. Algo que era intratável se tornou uma doença tratável com possibilidade de longevidade, o que foi surpreendente. No bojo disso tudo, a política mudava, as receitas mudavam, a política farmacêutica mudava, e eu procurei seguir tudo isso. Escrevi alguns artigos sobre essas questões, mas tenho um livro sobre HIV/Aids que ainda está em gestação.

Ao ler mais sobre a doença encontrei outra pequena toca de coelho para adentrar, que tinha a ver com a questão da experimentação científica. Co- 
mecei a ler artigos sobre os experimentos de laboratório realizados durante a Guerra Fria, sobre ensaios clínicos e sobre experimentação farmacêutica. Como se faz uma equiparação entre ratos e humanos e entre beagles e humanos? Como todos esses experimentos foram desenhados para nos dizer como chegamos a saber alguma coisa?

Finalmente, minha investigação sobre o mundo farmacêutico está profundamente ligada à minha pesquisa sobre o desenvolvimento da energia nuclear no Brasil (Coldstein, 2017b), que é o meu atual projeto. Ele me traz muitas questões importantes. As duas propostas se conectam entre si por serem fruto de leituras de trabalhos que não pertenciam ao meu campo de conhecimento. Procurei saber como a ciência se desenvolveu a partir da década de 1920. Estou interessada em saber como os produtos farmacêuticos foram desenvolvidos e como foi criada a pesquisa na Guerra Fria (Goldstein, 2007,2012 ). E isso tem me conduzido para campos do conhecimento em que eu possuía algum treinamento, mas nos quais não havia ousado pisar intelectualmente. Eu tive todas as aulas de antropologia médica em Berkeley, trabalhei nesse campo, mas o meu primeiro projeto teve como foco principal a antropologia cultural. Ainda assim, eu sempre pensei em questões de experimentação e produção de conhecimento. Por tudo isso espero poder juntar esses vários interesses nesta nova fase.

Há mais questões sobre produção de conhecimento em nosso campo agora. Este novo trabalho será mais sobre produção de conhecimento do que sobre questões baseadas em classe?

DG-Tanto as questões sobre experimentação quanto as questões acerca da contaminação e da toxicidade envolvem o trato de corpos, comunidades pobres e seus locais de residência. Antes, havia a preocupação de impedir o avanço da violência em regiões particulares. Creio que isso ainda está em andamento, mas agora parece que esses lugares também são transformados em zonas de sacrifício para diferentes tipos de contaminação (Goldstein, 2017a). Pedimos para certas pessoas doarem seus corpos à experimentação. Lá despejamos nosso lixo. Não acho que as questões de classe e as de produção do conhecimento estejam tão distantes uma da outra neste caso. De certo modo, neste projeto, estou trabalhando com alguns grupos de pessoas similares aos do Laughter Out of Place.

\section{O que acha que o projeto sobre energia nuclear acrescentará ao debate no Brasil?}

DG - No exterior ninguém imagina que o Brasil possui energia nuclear. Isso é o mais engraçado neste projeto. E meus amigos da classe média no Brasil não sabem sequer que existe uma usina no país. Meus amigos ambientalistas 
não a consideram um problema. Me espanta o fato de que todos pensam que isso não tem importância (Coldstein, 2017b).

\section{Você disse que, infelizmente, a etnografia nos diz algo que já conhecemos. Parece,} porém, que esse projeto está tentando chegar à raiz de algo desconhecido.

DG-É um bom ponto. Talvez agora eu realmente tenha oscilado o pêndulo para o outro lado. A primeira grande iteração com o mundo é: "Vamos dizer algo que todos conhecemos, mas apenas dizer". A segunda é: "Vamos todos olhar para o que não conhecemos, ou que não achamos possível, ou sobre o que não temos certeza, ou que nos disseram que é seguro, ou que nos disseram que era coisa do passado..."

Dentro de uma pequena e bonita área situada entre São Paulo e o Rio de Janeiro, há um belo conjunto de ilhas e um parque nacional que tem todo o tipo de diversidade étnica possível. Mas o ponto básico sobre isso é que estão construindo uma terceira usina nuclear em um local que já tem outras duas mais antigas. Todo mês transferem combustível por uma estrada estreita entre a instalação de reprocessamento e a usina nuclear. Muitas comunidades estão no caminho. Não se trata apenas da possibilidade de um acidente; acho que vale a pena explorar por que o Brasil considera que o seu projeto de modernidade não pode dispensar a energia nuclear. Ser um "gigante" que está despertando inclui essa questão. Muito temos ouvido sobre o que se ver, se pensar e se sentir como sendo um Estado. Mas nesse caso o aparato científico sustenta os termos desse projeto de modernidade. O que aconteceria se alguém dissesse: "Não, nós não seguiremos essa direção"?

O que também é muito interessante é que a esquerda e a direita - o ditador diabólico e a esquerda liberal reformista -, ambas querem a energia nuclear (Coldstein, 2017b). Parece existir um entusiasmo, como se nada catastrófico houvesse acontecido em lugar nenhum. Acho bem interessante que você possa estar no mundo, numa potência mundial, e que a história particular de qualquer pessoa possa ser apagada. É como se Chernobyl não tivesse acontecido; como se Fukushima não tivesse acontecido. O Brasil pode ter um ego maior porque tem muito território, enquanto os japoneses têm um número limitado de lugares para onde fugir em caso de desastre. Mesmo assim, essa construção nuclear está ocorrendo entre as suas duas principais cidades. E as usinas que eles vêm negociando vão percorrer toda a costa, na mesma direção em que foram distribuídas as capitanias hereditárias no século XVI. Na era colonial, você simplesmente daria centenas de quilômetros e desenharia linhas retas pelo estado. Assim, as usinas nucleares pontilham toda a área do primeiro título. É estranho, porém, porque até agora está tudo no plano imaginário. Acho que todos nós compartilhamos as seguintes ques- 
tões: O que faremos? Por que fazemos isso? Quem sacrificamos?

Costo muito da literatura sobre a história da Guerra Fria brasileira. Boa parte dela é bastante reveladora. Costo de ir aos arquivos e ver algumas dessas coisas, mesmo porque minha vida no Brasil começou na década de 1990 e eu acho fascinante a leitura sobre as épocas anteriores.

Acho que as pessoas que não são especialistas nesse período não pensam que o Brasil era uma presença na Guerra Fria.

DG -O Brasil estava presente em muitas explosões nucleares e em locais de testes, inclusive no teste nas Ilhas Marshall, feito pelos EUA. Havia um embaixador brasileiro assistindo ao teste no Atol de Bikini. Acho isto tão estranho quanto interessante.

Quero retornar ao artigo sobre o Trump que você escreveu recentemente com Kira Hall e Matthew Ingram, e o outro agora com Kira Hall. Há muitos antropólogos e sociólogos iniciando estudos a respeito dos apoiadores de Trump e observando criticamente esse momento da história dos EUA. O que o humor acrescenta a esses estudos acadêmicos?

DG - Sinto que o humor é crítico. Algo estava acontecendo, e havia uma desconexão entre o que pensávamos ver e o que Trump estava comunicando. Está muito claro para mim agora. Acho que ficou ainda mais claro no segundo artigo sobre Trump que escrevemos, no qual rastreamos sua semiótica pró-branco compreendida apenas pelos seguidores do candidato. O humor é interessante para pensar nisso porque a maioria dos nova-iorquinos, como eu mesma, concebeu Trump como um bufão, e mesmo como um bufão fracassado. Mas precisamos realmente nos esforçar para descobrir por que ele estava se comunicando tão bem com as outras partes do país - um país que, supostamente, odeia os nova-iorquinos. Bom, talvez exceto depois do 11 de Setembro, quando tivemos pessoas como o prefeito Rudy Guiliani, Nova York tenha reconquistado sua consideração nos EUA. Houve assim ali uma conexão entre a nação e o sentido semântico de Nova York, além do fato de Trump saber como sustentar um divertido espetáculo cômico, repleto de arremedo.

Estou falando aqui de uma posição muito específica sobre o tema. Acho que esquerdistas liberais viram Trump como: "Oh, com esse na corrida, vamos ganhar a eleição, está definido, nós vamos ganhar!”. Refiro-me particularmente a esquerdistas liberais brancos, porque acho que os negros foram mais inteligentes e viram Trump como problema bem mais cedo. Talvez os brancos liberais não tenham escutado, não tenham ouvido, talvez estivessem surdos. A maior parte das pessoas não estava preocupada, porque 
achava que Trump seria derrotado.

Essa é a narrativa que temos daqueles dias antes e após a eleição, mas nosso artigo começou antes disso. No artigo começamos por pensar: "Vamos apenas nos entreter com isso: por que ele está indo tão bem? O que ele está dizendo a essas pessoas?" Não fizemos um projeto como o de Arlie Hochschild para conversar com as pessoas e depois perguntar: "Quem é você e por que vota em um candidato como Donald Trump?"

Em vez disso fizemos algo mais caseiro: assistimos a 500 vídeos de Trump viajando por todo o país, com a mesma fala, usando adereços, estimulando o nacionalismo, criando um tipo de nostalgia pelas coisas passadas, criando uma nostalgia pela punição de minorias, criando um discurso que parecia muito pragmático e lógico nesse mundo, por mais ridículo que fosse para os liberais urbanos. Havia uma divisão de classe, uma divisão cultural e uma divisão semântica com relação à maneira como as pessoas leram tudo isso. Foi necessária a compreensão do humor para realmente visualizar tudo isso em conjunto. Além do mais, para ambos os lados, era estranhamente divertido, por mais perturbador que fosse.

Iniciamos este artigo dizendo: "Todos nós perguntamos: o que ele disse hoje? O que ele fez hoje? O que ele tuitou hoje?” E agora estamos assistindo ao espetáculo político: “Ele vai começar uma guerra nuclear hoje?”. Agora não é mais divertido. Não é uma questão estimulante. E não acho que tenha sido para nenhum de nós, porque é simplesmente assustador. Mas podemos ver que, para outros, Trump está sendo ol hado de um modo completamente diferente.

Também criamos narrativas inteiras muito diferentes. Você pode simplesmente mudar de canal e ver que a Fox está ficando mais astuta [(foxyfoxy]). A PBS está sempre dizendo que é seu último ano no mercado. Certamente também temos de pensar nos números do nosso próprio eleitorado. Muitas pessoas ficaram em casa; não votaram na eleição de Trump. Acho que os negros entenderam e ouviram a mensagem que estava sendo transmitida bem antes. A presença de Steve Bannon na Casa Branca é algo com que todos deveriam se preocupar, não apenas os liberais. O nepotismo está além de todos nós. Mesmo nosso sistema legal não parece apto para dar conta das fal has mais óbvias. Então, nos artigos que escrevemos, estamos lidando com o mundo semântico de Trump, com os apelos ao nacionalismo e ao racismo e com a nostalgia pela punição. Esses movimentos todos estão diretamente relacionados ao que Trump tem dito. Não acho que estamos à beira de todos esses problemas somente agora - ele antes já falava com base em algo real. 
Você concorda com o cientista político francês Bernard-Henri Lévy, que disse (numa entrevista n'O Globo) que a vitória de Donald Trump pode ser atribuída a um movimento mundial, uma revolução das ideias simples daqueles que buscam bodes expiatórios, dos racistas e de pessoas que desprezam a democracia?

DG-Sim, acho que tem algo a ver com isso. Certamente Lévy diz algumas coisas interessantes. Eu fiquei animada com a resistência holandesa ao personagem trumpista de direita que apareceu por lá e fico feliz que esse personagem trumpista tenha perdido. Também fiquei animada com a vitória de Macron na França, que oferece, eu acredito, a necessária resistência ao nacionalismo de direita na Europa.

Acho que há uma conexão entre o que estamos vivendo agora, após o neoliberalismo e após o grande impulso para a esquerda na América Latina. Houve esse momento de otimismo em que havia esquerdistas no poder na América Latina - você tinha Néstor e, depois, Cristina Kirchner na Argentina; Lula e Dilma Rousseff no Brasil. Ambas as presidentas deixaram o cargo sob condições humilhantes. Costaria de voltar um pouco à ideia de Lévy de que essa possa ser uma tendência mundial, e gostaria de destacar que, nesse momento específico, Trump acertou o tom nos EUA, e ele é um malandro, artífice das palavras.

É interessante nos atentarmos para a queda de Dilma no Brasil, à qual nos referimos, agora, como um golpe. Foi um conjunto de disposições que permitiu que ela acabasse sendo derrubada por uma tecnicidade, e por um verdadeiro tipo de personagem shakespeariano (Temer) que se aproximou dela e, em seguida, simplesmente a matou. E agora Bolsonaro... Mas o que me anima no Brasil é que haverá eleições, em 2020. Eu levo a sério as acusações de corrupção - não contra Dilma, porque contra ela acredito que se tratou realmente de uma tecnicidade - mas antes desse episódio, todos já tinham praticado o "pagar para governar". Entretanto, as coisas que aconteceram nos últimos trinta anos - e Lula, Dilma e todos os outros caíram nesse padrão-fazem-me pensar que, sim, por um lado, tratou-se sim de uma manobra conservadora para liquidar o PT. Por outro lado, há realmente algo que não funciona e que precisa ser corrigido, queira ou não a esquerda. Algo está realmente fora dos eixos. Eu também vou ter de escrever sobre isso para o projeto sobre energia nuclear porque, de algum modo. $O$ assunto passou a compor o meu problema, de algum modo. No escândalo nacional da Lava Jato se alegou que uma quantia considerável de recursos foi desviado do desenvolvimento da energia nuclear. Essa parte do escândalo é conhecida como Operação Radioatividade. Muitas partes do setor de energia estão envolvidas na denúncia; assim como está também a obra de construção da usina nuclear Angra 3. Muitas empreiteiras e participantes individuais enriqueceram com esses projetos (Coldstein, 2017b). 


\section{Qual tipo de violência da utopia liberal, para citar Zizek, está sendo gestado no nosso} mundo global?

DG - Acho que Zizek pode estar equivocado muitas vezes, mas nesse artigo "The Violence of the Liberal Utopia" (Zizek, 2008) - ele acertou. Acho que ele costuma dizer um monte de coisas muito levianamente, mas gosto desse artigo porque ele tenta chamar as pessoas a prestarem atenção para o que está acontecendo. É como se ele previsse a vitória de Trump por causa da ingenuidade que havia quanto à política econômica neoliberal. As violências da utopia liberal e neoliberal são muitas, mas uma delas é a cegueira que criamos. Parece que fomos sedados. Não gosto dessas teorias que dizem que temos de sofrer de verdade antes de voltarmos aos nossos sentidos. Mas, certamente você não vai se permitir relaxar num governo Trump. O que quero dizer é que acho que relaxei no governo Obama e talvez não devesse ter feito isso.

\section{Como você vê o futuro da antropologia nos EUA e no mundo?}

DG - Existe ainda um foco centrado no estado-nação. Mas eu acho que realmente as trocas são cada vez maiores e mais velozes. Todos nós estamos falando mais uns com os outros. Isso está nos colocando em contato com um grupo mais amplo de colegas e estimulando intercâmbios muito maiores, 0 que faz com que questões sobre como e quem citamos e sobre como respeitamos os outros nesse campo sejam centrais. Nos últimos dez anos tem havido cada vez mais intercâmbios de estudantes, que estão aproveitando a pós-graduação para receber treinamento em diferentes lugares -e, em si, essa troca é boa. O intercâmbio deve ser em múltiplas direções. Não deve ser nas direções coloniais habituais.

E em dez anos, o Brasil também mudou drasticamente. Eu diria que um dos principais feitos reais do governo Lula foi expandir o ensino universitário para áreas no Brasil que nunca antes haviam tido universidades importantes. É como se fizessem o Corpo de Paz (Peace Corps) para universidades no Brasil. Estive em universidades no Nordeste brasileiro que estavam incrivelmente empobrecidas em termos de recursos, bibliotecas e corpo docente. Agora, elas têm dinheiro e atraem pessoas, são instituições que se consolidaram e que têm formado grandes estudiosos e excelentes estudantes. Acho que é um grande e importante progresso.

A questão é: onde está a antropologia? Costaria de ver as áreas, os campos de estudo da disciplina sendo democratizadas de formas mais interessantes. A antropologia cultural nos EUA tem elementos que a tornam um meio difícil de navegar. Temos uma área de "celebridades". Criamos um campo de entretenimento, uma Atlantic City da antropologia onde temos 
"estrelas", trabalhadores e diferentes tipos de personagens, e não acho que isso seja sempre tão saudável. Mas a grande etnografia de qualidade ainda é ainda algo pelo qual vale a pena lutar. Sua beleza reside em ser algo entre a arte e a ciência, a poesia e a filosofia, a reflexividade e a objetividade. $\mathrm{O}$ sistema universitário, às vezes, não compreende isso e é, ele próprio, profundamente neoliberalizante em suas expectativas. Isso é deprimente para todos e cada um de nós. Mas eu me sinto cada vez mais comprometida com a pesquisa que estou desenvolvendo agora, e tento deixar de lado meus sentimentos a respeito da política universitária.

\section{REFERÊNCIAS BIBLIOCRÁFICAS}

BECK, Ulrich

2006 "Living in the World Risk Society". Economy and Society, 35(3):329-45.

2007 "Beyond Class and Nation: Reframing Social Inequalities in a Clobalizing World". British Journal of Sociology, 58(4):679-705.

\section{GOLDSTEIN, Donna M.}

2007 "Life or Profit? Structural Violence, Moral Psychology and Pharmaceutical Politics". Anthropology in Action, 14(3): 44-58.

2012 “'Experimentalité': Pharmaceutical Insights Into Anthropology's Epistemologically Fractured Self". In: LEVINE, Susan (ed.). Medicine and the Politics of Knowledge. Cape Town, South Africa, HSRC, pp.118-151.

2013 Laughter Out of Place: Race, Class, Violence and Sexuality in a Rio Shantytown. Berkeley and Los Angeles, University of California Press. (Trabalho original publicado em 2003).

2017a "Invisible Harm: Science, Subjectivity and the Things We Cannot See". Culture, Theory and Critique, 58(4): 1-8.

2017b "Fukushima in Brazil: Undone Science, Technophilia, Epistemic murk". Culture, Theory and Critique, 58(4): 1-22.

2017c "Conclusions: Anthropological Pasts and Futures". In: ENGLEHARDT, Joshua; RIECER, Ivy (eds.). These 'Thin Partitions': Bridging the Growing Divide between Cultural Anthropology and Archaeology. Boulder, University Press of Colorado, pp. 253-267.

2017d "Commentary: Science, Politics, and Risk: Catastrophic Asia From the Perspective of a Brazilianist Anthropologist". Special Issue: Catastrophic Asia. Journal of Asian Studies, 76(2): 481-497. 
2017e "Fieldnote as Political Weapon: James Comey's Ethnographic Turn". Dispatches [Cultural Anthropology Website]. Disponível em: https:// culanth.org/fieldsights/1162-fieldnote-as-political-weapon-jamescomey-s-ethnographic-turn. Acesso em xx de mês de ano.

GOLDSTEIN, Donna M.; HALL, Kira

2017 "Post-Election Surrealism and the Hands of Donald Trump". HAU: Journal of Ethnographic Theory, 7(1): 397-406.

GOLDSTEIN, Donna M.; STAWKOWKSI, Magdalena E.

2015 "James V. Neel and Yuri E. Dubrova: Cold War Debates and the Cenetic

Effects of Low-Dose Radiation". Journal of the History of Biology, 48(1): 67-98.

HALL, Kira; COLDSTEIN, Donna M; INGRAM, Matthew Bruce

2016 "The Hands of Donald Trump: Entertainment, Cesture,

Spectacle," HAU: Journal of Ethnographic Theory, 6, (2): 71-100.

INGOLD, Tim

2014 "That's enough about ethnography!". HAU: Journal of Ethnographic Theory, 4 (1): 383-395.

JACKSON JR., John L

2012 "Ethnography is, Ethnography Ain't". Cultural

Anthropology, 27, n.3: 480-497.

MCGRANAHAN, Carole

2015 "Ethnography as Theoretical Storytelling". Savage Minds Writers' Workshop series essays. Formato eletrônico. Disponível em: https://savageminds.org/2015/10/19/anthropology-astheoretical-storytelling/. Acesso em xx de mês de ano.

NIXON, Rob

2011 Slow Violence and the Environmentalism of the Poor.

Cambridge, MA, Harvard University Press.

ORTNER, Sherry

1984 "Theory in Anthropology Since the Sixties". Comparative Studies in Society and History, vol. 26, n. 1:126-166. 
ENTREVISTA | Entre o riso e o trágico: perspectivas sobre modos

de vida no Brasil | Entrevista com Donna M. Coldstein

PEIRANO, Mariza

1995 A Favor da Etnografia. Rio de Janeiro, Relume-Dumara. 